\title{
THE METHOD OF THE PROPOSITIONAL FRAME MODELING IN TEACHING A FOREIGN LANGUAGE ${ }^{1}$
}

\author{
Lyudmila A. Araeva \\ Kemerovo State University, Kemerovo, Russia \\ Stanislav I. Li \\ Kemerovo State University, Kemerovo, Russia
}

\begin{abstract}
The article describes the method of the propositional frame modeling and its application in teaching a foreign language, including the languages of the indigenous minorities of Russia. The material of the frame "berry" offers guidelines for its use in the classroom for studying foreign languages. The use of this method in teaching foreign languages helps pupils to more accurately and more deeply understand the structural, substantive and functional patterns that dominate them, helps students develop language guessing based on word formation, which is a universal way of expanding their potential vocabulary. Derived and non-derivative words are built according to the same deep structural-logical schemes - propositional structures, on the basis of which propositions are created. Propositional structures have a universal nature for all natural languages, but they are implemented quite specifically in sentences in a given language under the influence of territory, climate, life experience, and established cultural traditions of a people. Recognition of propositional structures and propositions within the frames in the semantics of derivatives of the native language and a foreign language makes it possible to see what is common in the knowledge of the world of all nations and to reveal the unique "world" of the language.

Key words: propositional structure, proposition, frame, method of propositional-frame modeling, foreign language, languages of indigenous peoples, Teleut language, linguistic view of the world.

Citation. Araeva L.A., Li S.I. The Method of the Propositional Frame Modeling in Teaching a Foreign Language. Vestnik Volgogradskogo gosudarstvennogo universiteta. Seriya 2, Yazykoznanie [Science Journal of Volgograd State University. Linguistics], 2019, vol. 18, no. 1, pp. 187-195. (in Russian). DOI: https://doi.org/ 10.15688/jvolsu2.2019.1.16
\end{abstract}

\section{МЕТОД ПРОПОЗИЦИОНАЛЬНО-ФРЕЙМОВОГО МОДЕЛИРОВАНИЯ В ОБУЧЕНИИ ИНОСТРАННЫМ ЯЗЫКАМ ${ }^{1}$}

\author{
Людмила Алексеевна Араева \\ Кемеровский государственный университет, г. Кемерово, Россия \\ Станислав Игоревич Ли \\ Кемеровский государственный университет, г. Кемерово, Россия
}

Аннотация. В статье описывается метод пропозиционально-фреймового моделирования в обучении
иностранным языкам, в том числе языкам коренных малочисленных народов России. Универсальность это-
го метода обусловлена тем, что производные и непроизводные слова строятся по одинаковым глубинным
структурно-логическим схемам - пропозициональным структурам и созданным на их основе пропозициям.
На материале фрейма «ягода» показаны возможности применения метода в двух направлениях: «реализация
одной пропозициональной структуры в названиях разных объектов в разных языках» и «реализация разных 
пропозициональных структур в названиях одного объекта в разных языках». Предложены методические рекомендации по применению данного метода на занятиях по изучению иностранных языков, нацеленные на формирование у обучающихся знаний о доминирующих в разных языках структурно-содержательных и функциональных закономерностях, на развитие у обучающихся навыка языковой догадки на основе знаний о словообразовательной структуре слова, что составляет универсальный способ расширения их потенциального словаря. Распознавание пропозициональных структур и пропозиций в границах фреймов в семантике дериватов родного и иностранного языков дает обучающимся возможность увидеть общее в познании мира всех народов и выявить уникальный этнический мир того или иного языка.

Ключевые слова: пропозициональная структура, пропозиция, фрейм, метод пропозиционально-фреймового моделирования, иностранный язык, языки коренных малочисленных народов, телеутский язык, языковая картина мира.

Цитирование. Араева Л. А., Ли С. И. Метод пропозиционально-фреймового моделирования в обучении иностранным языкам // Вестник Волгоградского государственного университета. Серия 2, Языкознание. - 2019. - Т. 18, № 1. - С. 187-195. - DOI: https://doi.org/10.15688/jvolsu2.2019.1.16

\section{Введение}

Глобализация - явление неоднозначное. Результатом ее становится, с одной стороны, унификация этнокультур, а с другой - возрастание интереса социума к ним. Современный мир переживает своеобразное этническое возрождение. Это находит отражение, в частности, в государственных программах по сохранению языка и культуры коренных малочисленных народов России. В утвержденной Правительством РФ «Стратегии социально-экономического развития Сибири до 2020 года» среди приоритетов предусмотрено сохранение языка и культуры народов Севера. При полномочном представителе президента в Сибирском федеральном округе работает консультативно-экспертный совет по делам малых народов. Заинтересованность в сохранении и развитии таких культур со стороны их носителей и мирового сообщества в целом обусловлена тем, что этнокультурное разнообразие - одно из важных условий жизнеспособности современной земной цивилизации. Всеобщая декларация о культурном разнообразии, принятая ЮНЕСКО в 2001 г., является правовым документом, в котором культурное разнообразие признается «общим достоянием человечества», его охрана - конкретным этическим обязательством, не отделимым от уважения человеческого достоинства.

Одно из условий сохранения традиций коренных малочисленных народов России изучение их языков и обучение им. Как правило, языки малочисленных народов используются только в быту представителями стар- шего и отчасти среднего поколения. К таким языкам относится телеутский язык. В настоящее время насчитывается примерно 2600 телеутов, основная часть которых проживает в России на территории Кузбасса. Телеуты (примерно 1500 человек) компактно проживают в с. Беково Беловского района Кемеровской области. Они занимаются огородничеством и животноводством, разведением овец, кур, уток, лошадей. Сохранились национальные свадебные обряды, обряд погребения, лечение аласом. Телеуты помнят свои роды (сеоки), существует алфавит телеутского языка, но большая часть представителей этой народности не умеет писать на родном языке. В общеобразовательной школе с. Беково телеутский язык преподается в виде спецкурса. Однако учебники, по которым он изучается, составлены без учета современных методик и ориентированы преимущественно на механическое запоминание.

Как писал В. фон Гумбольдт, на самом абстрактном уровне все языки устроены одинаково, и поэтому можно говорить о едином человеческом языке. «Формы нескольких языков могут совпадать в какой-то еще более общей форме, и к одной форме восходят, по существу, формы всех языков, если только идет речь о самых общих чертах: о связях и отношениях представлений, необходимых для обозначения понятий и для построения речи» [Гумбольдт, 1984, с. 74]. Любой человек, изучая другой язык, сравнивает его с родным языком, поэтому появляются различные мнемонические методики, позволяющие достаточно легко запоминать те или иные иност- 
ранные слова по ассоциации со словами родного языка. Несомненно, применение мнемонической методики имеет положительные результаты. Однако данная методика достаточно субъективна. «Образы-ассоциации обычно носят индивидуальный характер, каждый может придумать свои, главное, чтобы они были интересные и яркие. Например, число 32 легко запомнить, ведь это 3 веселых гуся» [Голубева, 2019].

Наша задача - представить один из объективных универсальных методов изучения языков применительно к языкам коренных малочисленных народов России.

\section{Лингвистические и психологические основы пропозиционально-фреймового моделирования}

Словообразование в методике преподавания иностранных языков играет ведущую роль прежде всего потому, что в любом развитом языке значительная часть словарного состава представлена производными единицами либо устойчивыми словосочетаниями, построенными по однотипным деривационным моделям. Серийное образование производных единиц и устойчивых словосочетаний проявляет работу мысли по аналогии. Благодаря принципу аналогии человек категоризует и интерпретирует окружающую действительность, нередко прибегая к использованию языковой догадки. Развитие у обучающихся иностранному языку навыка языковой догадки на основе словообразования - универсальный способ расширения их потенциального словаря. Вслед за Л.Г. Ворониным и И.И. Богдановой, под языковой догадкой мы подразумеваем непосредственное понимание семантики слов, которые не встречались в речевой практике обучающихся или встречались в других комбинациях [Воронин, Богданова, 1971]. Основной причиной непонимания и неусвоения нового производного слова является неумение распознать в нем словообразовательную модель и ее компоненты, отсутствие знаний деривационных закономерностей в изучаемом языке.

Овладение инструментами и законами продуктивного словообразования, знание основных категоризаторов в иностранном язы- ке «дает в руки учащихся средство не простого механизма накопления словарных единиц, а возможность систематизации и творческого использования уже накопленного словаря, позволяет глубже понять семантику знакомых слов и дает возможность семантизации значительной части новой лексики, понимание не отдельных единиц, а целых классов слов» [Хидекель, 1975, с. 18].

Для того, чтобы обучающиеся запомнили новые слова, преподаватель семантизирует их, как правило, двумя способами - беспереводным и переводным. Беспереводной способ заключается в демонстрации картинок, рисунков, действий, жестов или предметов, в использовании дефиниции слова, его синонимов, актуализации внутренней формы слова, а также ассоциативной памяти обучающихся. При переводном способе подбирается слово-эквивалент в родном языке, используются механизмы ассоциации: на основе контраста (красивыц - урод), сходства (ясный день солнечный день), соподчиненности (учитель - ученик), гипо-гиперонимии (овощ огуреи, ивет - красный), переноса по признакам 'причина - следствие' (болезнь смерть), 'предмет - материал' (блюдие стекло), 'действие - объект' (пить - кофе), 'действие - место' (учиться - школа), 'целое - часть' (университет - студент).

Таким образом, при изучении иностранного языка используется механизм познания мира человеком, в основе которого находится метафорическая либо метонимическая связь лексических единиц в высказывании. Этот механизм актуализируется при соотношении семантики производного слова с семантикой производящего.

В основе пропозиционально-фреймового метода обучения иностранному языку лежит апперцепция - одно из фундаментальных свойств психики человека, благодаря которому поступающая новая информация соотносится и взаимодействует с ранее полученными знаниями, с уже созданной понятийной системой. Соотношение называемого предмета либо явления с уже созданными в языке хорошо представлено через предикативную связанность функциональной семантики производного слова с производящим. Производная лексика позволяет «увидеть, как была воспринята 


\section{МАТЕРИАЛЫ И СООБЩЕНИЯ}

определенная реалия в мире “как он есть" через отсылки к каким (исходным, мотивирующим) сущностям (объектам, действиям, качествам и т. д.) они были осмыслены и затем поименованы» [Кубрякова, 2006, с. 6].

Производные слова, равно как и типизированные устойчивые словосочетания, сформированы по универсальным для всех языков структурно-логическим схемам - пропозициональным структурам (далее - ПрС), которые выражены в языке вербализованными суждениями - пропозициями. Пропозициональные структуры - наиболее абстрактные, предикативно связанные субъектнообъектные отношения, проявляющие дискурсивность мыслительной деятельности человека, - едины для всех представителей современной цивилизации.

По словам Е.С. Кубряковой, словообразовательные модели разного типа можно рассматривать как формулы регулярной свертки пропозициональной структуры при ее актуализации не в пределах конкретного предложения, а отдельным ПС (производным словом), универбом. ПС - это по существу краткая дескрипция обозначаемого, за которой стоят более полные и более развернутые знания о нем, они-то и должны быть «восстановлены» или, по крайней мере, уточнены в акте понимания ПС. Извлечение информации из ПС обязательно требует инференции, то есть некоторого домысливания реального содержания словообразовательной конструкции. Понимание производного слова может быть уподоблено пониманию метонимии или синекдохи в лексике: по целому мы догадываемся о частях, по частям - о целом [Кубрякова, 2004, с. 412].

Семантическое наполнение одной и той же пропозициональной структуры и, соответственно, предикативная связанность актантов могут быть как различными, так и идентичными в разных языках.

\section{Возможности применения пропозиционально-фреймового моделирования в практике обучения телеутскому языку}

Возможности метода рассмотрим на примере наименований ягод в телеутском языке на фоне именований ягод в разных языках ${ }^{2}$.
Слова, эксплицирующие фрейм «ягода», оформляются с помощью специализированных формантов: в русском - чаще суффиксом -ик/a/, реже суффиксами -ин/a/, -ниц/a/, -ник, в китайском - суффиксоидом 莓 [méi] [Араева, Ли, 2014], в хакасском - суффиксоидом чистек, в английском - суффиксоидом berry. В телеутском языке для значительного числа наименований ягод используется суффиксоид јиилеги. В отличие от суффиксов суффиксоиды могут выступать в высказывании в качестве самостоятельных слов, но при этом выполняют функцию суффиксов, которая заключается в создании типизированных устойчивых словосочетаний либо производных слов. В контексте нашего исследования важно не то, что оформляют суффиксоиды (производные слова либо устойчивые словосочетания), a то, что с их помощью создаются серийные производные слова либо устойчивые словосочетания.

Использование метода возможно в двух направлениях: «одна пропозициональная структура - название разных ягод в разных языках» и «разные пропозициональные структуры - название одной ягоды в разных языках».

1. Использование пропозициональнофреймового метода целесообразно начать с характеристики отдельных пропозициональных структур, в направлении «одна пропозициональная структура - название разных ягод в разных языках».

ПрС «объект - признак» может реализоваться по-разному: в качестве признака может актуализироваться цвет, вкус, форма плода.

ПрС «объект - признак», где признак представлен как цвет, реализуется в названии ягоды голубики в русском, китайском, алтайском $^{3}$, телеутском, английском языках: русский - голубика, китайский - 蓝莓 [lánméi] (蓝. [lán] - 'голубой, синий'), алтайский - кок кат (кок - 'голубой, синий'), английский blueberry (blue - 'голубой'), телеутский чанкыр јиилеги (чанкыр - 'голубой'). Один и тот же цвет в разных языках может характеризовать как одни и те же, так и различные ягоды. Например, в китайском и английском языках ежевику называют черной ягодой: китайский - 黑莓 [hēiméi] (黑 [hēi] - 'черный', 莓 [méi] - 'ягода'), английский - blackberry 
(black - 'черный'). Пример цветового расхождения в именованиях ягоды по цвету обнаруживают именования черники, ср.: английский blueberry (blue - 'голубой'), русский - черника, алтайский - карагат (кара - 'черный').

ПрС «объект - признак», где признак представлен как вкус, реализуется в названии крыжовника, например, китайский - 醋薄 [cùméi] (醋 $[$ cù] - 'уксус', 'ягода, по вкусу напоминающая уксус, кислая ягода'), или смородины, например, русский - кислица.

ПрС «объект - признак», гдепризнак представлен как структура плода, реализуется в названии ягоды костяники, например, английский - stoneberry (stone - 'камень'), то есть 'каменная ягода', в именовании актуализируется твердость косточки, находящейся в ягоде. Интересно отметить, что в тверских говоpax русского языка костянику называют каменицей. В китайском языке в основе наименования этой ягоды находится метафорическая пропозиция 'малина, рожденная камнем': 石生悬钩子 [shí shēng xuángōuzī] (石 [shí] 'камень', 生 [shēng] - 'рождаться', 悬钩子. [xuángōuzǐ] - 'малина пальчатая').

ПрС «объект - предикат - место», также может реализовываться по-разному. Например, земляника в русском, хакасском, шорском, алтайском языках - ягода, которая растет на земле, близко к земле, ср.: русский - земляника, хакасский - чир чистегі (чир - 'земля'), шорский - чер честеги (чер - 'земля'), алтайский - јер јиилек (јер - земля). Земляной ягодой телеуты называют клубнику: јер јиилеги (јер - 'земля'). В китайском и английском языках клубника и земляника - это ягоды, которые растут в соломе, траве: английский - strawberry (straw - 'солома'), китайский 草苜 [căo méi] (草 [căo] - 'трава, солома').

В телеутском языке при именовании земляники ПрС «объект - предикат - место» актуализируется как 'ягода, которая растет там, где пасутся бараны': кой јиилеги (кой - 'баран').

ПрС «объект - предикат - место» может конкретизироваться как 'ягода, которая растет на кустарнике', ср.: китайский - 树䓅 [shù méi] (树 [shù] - 'дерево, куст'); телеутский - агаш јилеги (агаш - 'куст'), хакасский - агас чистегі (агас - 'дерево, кустарник’). В процессе именования ягод возможно совмещение ПрС «объект - признак» и ПрС «объект - предикат - место», например, в телеутском языке костяника названа по месту и цвету - јер кыз ланат (јер - 'земля', кыз 'красный').

ПрС «объект - предикат - объект» также имеет различные реализации. При именовании ежевики в русском языке ПрС актуализирована как 'объект, характеризующийся по признаку другого объекта': ежевика 'ягода колючая, как еж'; в английском - как 'объект, характеризуемый через соположение с другим объектом': dewberry (dew - 'роса'), аналогичная этой реализация представлена и в русском именовании росяника, то есть в производных словах выражается связь растения с росой, которая покрывает по утрам стелющиеся ягодные плети.

ПрС «объект - предикат - объект» peaлизуется в именованиях ягод на основе номинаций животных, которые ею питаются, например, в хакасском языке так образованы названия земляники: тӥлгё чистегі ('ягода, которой питается лиса', тӥлгё - 'лиса'), костяники - хусхачах чистегі ('ягода, которой питаются птички', хусхачах - 'птичка') и ежевики - кӧрӥк јиилек ('ягода барсука', кӧрӥк 'барсук').

ПрС «объект - предикат - время" служит основой для наименования ягод, отражая знания этноса о времени их созревания. Эта пропозициональная структура реализуется, например, в английском именовании ягоды ирги: juneberry ('ягода, которая созревает в июне', june - 'июнь').

ПрС «объект - воздействие на человека» представлена в названии голубики в русском языке - пьяника, пьяница ('ягода, которая опьяняет'), малины в английском языке - wineberry (wine - 'вино'). Сравнение по средству воздействия обусловлено, по-видимому, культурой употребления спиртных напитков в Европе.

ПрС «объект - предикат - средство» реализуется в наименовании крыжовника в английском языке - gooseberry ('гусиная ягода'). Эту номинацию можно объяснить тем, что в Англии из крыжовника готовили соус для блюд из гуся.

Методические рекомендации: (1) учитель предлагает учащимся (самостоятельно 


\section{МАТЕРИАЛЫ И СООБЩЕНИЯ}

или совместно с ним) проанализировать словообразовательную структуру производных именований ягод и определить, какой признак положен в основу номинации; выявить представленные в семантике мотивирующих слов признаки, отраженные в именованиях ягод: цвет, форма, запах, место произрастания, размер плода, вкусовые качества, производимый эффект, животное, питающееся ягодой, болезнь, излечиваемая с помощью ягоды, и др. (например, используя метафорические выражения (загадки), в которых один объект охарактеризован через другой, имеющий с ним какое-либо сходство, учитель предлагает учащимся записать номинации, обозначающие ягоды); установить пропозициональные структуры, реализуемые в именованиях ягод в том или ином языке (языках); (2) сопоставив названия ягод в нескольких языках, определить общие и различные признаки; (3) ответить на вопрос о том, почему данный признак оказался значимым для того или иного этноса. Такая работа со словами одной тематической группы, организованная учителем с учетом фреймового характера процесса образования производного слова (подробно об этом см. также [Араева, Логунов, 2011]), позволит обучающимся не только усвоить лексический материал, но и понять, что в основе номинаций лежат знания носителей языка об объектах окружающего мира, а выбор мотивирующего признака имеет субъективный характер.

2. Возможности использования пропозиционально-фреймового метода в направлении «разные пропозициональные структуры - название одной ягоды в разных языках» проиллюстрируем на примере названий клюквы.

В номинациях ягоды клюквы в разных языках находят реализацию разные пропозициональные структуры. Так, ПрС «объект предикат - место» конкретизируется в семантике производного, называющего клюкву, в телеутском языке: сас јиилеги (сас - 'болото', јиилеги - 'ягода'), то есть для телеутов клюква - это ягода, которая растет на болоте. Для носителей английского языка клюква - это тоже ягода, которая растет на болоте: bogberry (bog - 'болото', berry - 'ягода'). Для носителей хакасского и шорского языков клюква - ягода, растущая во мху: в хакасском хайдынхады (хайдын - 'мох', хады - 'яго- да'), в шорском - торбас честеги (торбас 'мох', честеги - 'ягода'). В этих языках место произрастания клюквы конкретизируется - во мху. В русских говорах клюкву называют подснежницей, поскольку зимой эта ягода находится под снегом.

ПрС «объект - предикат - время» реализуется в русских говорах, где клюкву называют веснянкой (ее собирают, когда снег еще окончательно не растаял).

ПрС «объект - предикат - объект» реализуется в русских народных говорах: журавлина, журавлиха, и в английском языке: cranberry (cran - 'журавль', berry - 'ягода'), mooseberry (moos - 'лось', berry - 'ягода'), где клюква может быть названа на основе номинации животных, которые ею питаются. Следует отметить, что выбор ПрС, отражаемой в процессе номинации, обусловлен особенностями территорий, на которых проживают те или иные народности, и климатическими условиями (например, в местах проживания телеутов есть болота, но не водятся журавли).

ПрС «объект - признак» реализуется в китайском языке, где клюква названа по признакам цвета и размера (полипропозициональная структура): 小红莓 [xiăohóngméi] - 'клюква', 小 [xiăo] - 'маленький', 红 [hóng] - 'красный' ('маленькая ягода красного цвета').

ПрС «объект - действие» реализуется также в китайском языке, где клюква называется не только по размеру и цвету, но и по способу роста: 蔓越莓 [mànyuèméi] - 蔓越 [mànyuè] - 'ползти' ('ягода, которая ползет').

Итак, при именовании клюквы реализуется жизненный опыт носителей того или иного языка, в результате эта ягода называется по разным основаниям. В некоторых языках наблюдается словообразовательно-пропозициональной синонимия (СПС). Язык стремится к многоаспектному представлению одного и того же предмета действительности разными производными единицами. Мотивирующие единицы в случае СПС служат для демонстрации именуемого предмета (явления) с разных сторон. Носитель языка активизирует мотивирующий признак в зависимости от ситуации и цели коммуникации [Араева, 2015, с. 155]. В рамках пропозиционально-фреймового моделирования синонимия рассматривается как 
ситуативно-обусловленное явление. Отношения между слотами внутри фрейма порождают новые смыслы одного и того же предмета действительности через ассоциативные связи. «Фактически все, что имеется имплицитного в языке, становится эксплицитным при помощи ассоциаций. Одни из этих ассоциаций подсказываются самим языком, другие образуются в процессе функционирования, в речи» [Балли, 1955, с. 206]. При номинации в зависимости от условий реальной действительности происходит активизация определенного слота, который становится актуальным в каждом конкретном контексте. Таким образом, клюква именуется по месту произрастания (мох, болото) и нахождения (под снегом), времени сбора (весна), цвету (красная), представителю животного мира, поедающего эту ягоду (журавль, лось), размеру (маленькая), способу роста (ползет).

Методические рекомендации: учитель на основе проделанного анализа предлагает учащимся выявить, какие характерные для клюквы признаки реализуются в различных языках (значимость этих признаков можно подтвердить картинками с изображением клюквы), составить на изучаемом языке диалоги с использованием разных названий клюквы. Анализ номинаций одного объекта посредством актуализации разных пропозициональных структур, изучение семантики производных единиц в границах разных языков позволят обучающемуся убедиться в том, что механизм познания мира человеком един.

\section{Выводы}

При использовании пропозициональнофреймового метода в обучении иностранному языку рекомендуем придерживаться следующих шагов:

- формирование мотивирующей базы признаков, положенных в основу номинации того или иного объекта;

- представление связи объектов действительности через актуализацию семантической и формальной связи мотивирующих и мотивированных (производящих и производных) слов;

- демонстрация разных типов пропозициональных структур, которые лежат в основе наименований, входящих в один фрейм;
- демонстрация связи номинаций с другими номинациями за пределами фрейма;

- включение наименования в коммуникативную практику.

Использование пропозиционально-фреймового метода как универсального объективного метода преподавания языков позволяет включить языки малых народов в общелингвистический контекст, дает возможность обучающимся, проникая в семантику производного слова, осмыслить, во-первых, этапы номинации, которые прошел какой-либо объект действительности в сознании носителя языка, а именно: этап классификации и категоризации, этап связывания одного предмета с другим посредством ассоциаций, что ведет к появлению новых смыслов и значений, этап создания новых слов по аналогии и т. д., а во-вторых, понять общие закономерности познания мира представителями разных наций.

Преподавателю в процессе обучения любому языку необходимо обращать внимание учащихся на различия на уровне пропозициональных структур, наполнение которых зависит от специфики конкретных культур, климата, географического положения, и на то, что компактные пропозиционально-семантические объединения в одних языках могут иметь индивидуальную оформленность, в других такая оформленность размыта: есть прототипичные и периферийные для языкового сознания формальные средства. В результате применения метода пропозиционально-фреймового моделирования преподаватель формирует у обучающегося представление о том, что в каждом языке пропозициональные структуры отражают лишь некоторые признаки, свойства и т. д. объектов реального мира, поэтому картина мира, отраженная в отдельном языке, отличается от мира действительного и от картин мира, отраженных в других языках, то есть в каждом языке создается оригинальная пропозиционально организованная этническая языковая картина мира.

\section{ПРИМЕЧАНИЯ}

${ }^{1}$ Исследование выполнено при поддержке РФФИ, проект №17-04-00253ไОГН «Язык и культура телеутов». 
2 Языковой материал для анализа извлечен из следующих лексикографических источников: Баранова 3. И., Котов А. В. Большой русско-китайский словарь. М. : Живой язык, 2010. 568 с.; Китайско-русский словарь / под ред. Ся Чжунъи. Пекин : Шаньшу ишугуань, 2008. 1280 с.; Мюллер В. К. Полный англорусский русско-английский словарь: 300000 слов и выражений. М. : Эксмо, 2013. 1328 с.; Русско-алтайский словарь / под ред. Н. А. Баскакова. М. : Сов. энцикл., 1964. 875 с.; Русско-телеутский словарь / под ред. Л. Т. Рюминой-Сыркашевой, Н. М. Рюмина. Кемерово : Кузбассвузиздат, 2002. 192 с.; Русско-хакасский словарь / под ред. Д. И. Чанкова. М. : Гос. изд-во иностр. и нац. слов., 1961.968 с.; Телеутско-русский словарь / под ред. Л. Т. Рюминой-Сыркашевой. Кемерово : Кузбассвузиздат, 1995. 118 с.; Хакасско-русский словарь: 14000 слов; с приложением очерка «Хакасский язык» / сост. Н. А. Баскаков, А. И. Инкижекова-Грекул ; под ред. Н. А. Баскакова. М. : Гос. изд-во иностр. и нац. слов., 1953. 487 с.; Шорско-русский и русско-шорский словарь / сост. Н. Н. Курпешко-Таннагашева, Ф. Я. Апонькин. Кемерово : Кемер. кн. изд-во, 1993. 149 с.; Этимологический словарь тюркских языков: Общетюркские и межтюркские основы на букву «В», «Г» и «Д» / АН СССР. Ин-т языкознания ; ред. Н. З. Гаджиева. М. : Наука, $1980.395 \mathrm{c}$.

${ }^{3}$ В статье не разграничиваются южно-алтайский и северо-алтайский языки, поскольку критерии такого разграничения противоречиво представлены в лингвистике.

\section{СПИСОК ЛИТЕРАТУРЫ}

Араева Л. А., 2015. Одна из самых загадочных сфер языка (к вопросу о словообразовательно-пропозициональной синонимии) // Язык в пространстверечевых культур: К 80-летиюВ. Е. Гольдина / отв. ред. О. Ю. Крючкова, Л. П. Крысин. М. ; Саратов : Амирит. С. 154-164.

Араева Л. А., Ли С. И., 2014. Пропозициональнофреймовый анализ производного слова (на материале наименований ягод в китайском и русском языках) // Вестник Кемеровского государственного университета культуры и искусств. № 27. С. 124-126.

Араева Л. А., Логунов Т. А., 2011. Пропозиционально-фреймовый анализ производного слова как источник информации (на материале наименований ягод в английском и русском языках) // Актуальные проблемы современного словообразования : сб. науч. ст. / под общ. ред. проф. Л.А. Араевой. Вып. 4. Кемерово: Офсет. С. 96-99.

Балли Ш., 1955. Общая лингвистика и вопросы французского языка. М. : Изд-во иностр. лит. 416 с.
Воронин Л. Г., Богданова И. И., 1971. Догадка и ее физиологические механизмы // Новые исследования в психологии и возрастной физиологии. № 2. С. 128-130.

Голубева М. В., 2019. Техника запоминания информации, или что такое мнемоника // Советы психолога. URL: https://psychologist.tips/2262tehnika-zapominaniya-informatsii-ili-chto-takoemnemonika.html (дата обращения: 12.03.2019).

Гумбольдт В. фон, 1984. О различии строения человеческих языков и его влиянии на духовное развитие человечества: Форма языка // Избранные труды по языкознанию. М. : Прогресс. С. 69-74.

Кубрякова Е. С., 2004. Язык и знание: На пути получения знаний о языке: Части речи с когнитивной точки зрения. Роль языка в познании мира / Рос. Академия наук. Ин-т языкознания. М. : Языки славянской культуры. 560 с.

Кубрякова Е. С., 2006. Образы мира в сознании человека и словообразовательные категории как их составляющие // Известия РАН. Серия литературы и языка. Т. 65, № 2. С. 3-13.

Хидекель С. С., 1975. Некоторые спорные вопросы строения словообразовательных моделей и практика преподавания иностранного языка // Словообразование и его место в курсе обучения иностранному языку. Владивосток : ДВГУ. Вып. 3. С. 18-26.

\section{REFERENCES}

Araeva L.A., 2015. Odna iz samykh zagadochnykh sfer yazyka (k voprosu o slovoobrazovatelnopropozitsionalnoy sinonimii) [One of the Most Mysterious Spheres of the Language (to the Issue of Word-Formation-Propositional Synonymy)]. Yazyk $v$ prostranstve rechevykh kultur: K 80-letiyu V.E.Goldina. Moscow, Saratov, Amirit Publ., pp. 154-164.

Araeva L.A., Li S.I., 2014. Propositional Frame Analysis of Derived Words (Based on the Names of Berries in Chinese and Russian). Vestnik Kemerovskogo gosudarstvennogo universiteta kultury $i$ iskusstv [Bulletin of Kemerovo State University of Culture and Arts], no. 27, pp. 124-126.

Araeva L.A., Logunov T.A., 2011. Propozitsionalnofreymovyy analiz proizvodnogo slova kak istochnik informatsii (na materiale naimenovaniy yagod $\mathrm{v}$ angliyskom i russkom yazykakh) [Proposal-Frame Analysis of the Derived Word as a Source of Information (Based on the Names of Berries in English and Russian)]. Aktualnye problemy sovremennogo slovoobrazovaniya: 
Л.А. Араева, С.И. Ли. Метод пропозиционально-фреймового моделирования в обучении иностранным языкам

sbornik nauchnykh statey. Kemerovo, Ofset Publ., iss. 4, pp. 91-94.

Balli Sh., 1995. Obshchaya lingvistika i voprosy frantsuzskogo yazyka [General Linguistics and Questions of the French Language]. Moscow, Izd-vo Inostrannoy literatury. $416 \mathrm{p}$.

Voronin L.G., Bogdanova I.I., 1971. Dogadka i ee fiziologicheskie mekhanizmy [Guessing and Its Physiological Mechanisms]. Novye issledovaniya $v$ psihologii $i$ vozrastnoy fiziologii, no. 2, pp. 128-130.

Golubeva M.V., 2019. Tekhnika zapominaniya informatsii, ili chto takoye mnemonika [Technique of Memorizing Information, or What is Mnemonics]. Sovety psikhologa. URL: https:/ /psychologist.tips/2262-tehnika-zapominaniyainformatsii-ili-chto-takoe-mnemonika.html (Accessed 12 March 2019).

Humboldt W. von., 1984. O razlichii stroeniya chelovecheskikh yazykov i ego vliyanii na dukhovnoe razvitie chelovechestva: Forma yazyka. Izbrannye trudy po yazykoznaniyu [Selected Works on Linguistics]. Moscow, Progress Publ., pp. 69-74.
Kubryakova E.S., 2004. Yazyk i znanie: Na puti polucheniya znaniy o yazyke: Chasti rechi s kognitivnoy tochki zreniya. Rol yazyka $v$ poznanii mira. [Language and Knowledge: Towards Knowledge of the Language: Parts of Speech from a Cognitive Point of View. The Role of Language in the Knowledge of the World]. Moscow, Yazyki slavyanskoy kultury Publ. 560 p.

Kubryakova E.S., 2006. World Representations in the Human Mind and Categories of Word-Formation as Their Constituents. Izvestiya RAN. Seriya literatury $i$ yazyka [Bulletin of the Russian Academy of Sciences: Studies in Literature and Language], vol. 65, no. 2, pp. 3-13.

Hidekel S.S., 1975. Nekotorye spornye voprosy stroeniya slovoobrazovatelnykh modeley i praktika prepodavaniya inostrannogo yazyka. [Some Controversial Issues of the Structure of Word-Formation Models and the Practice of Teaching a Foreign Language]. Slovoobrazovanie i ego mesto v kurse obucheniya inostrannomu yazyku. Vladivostok, DVGU Publ., iss. 3, pp. 18-26.

\section{Information about the Authors}

Lyudmila A. Araeva, Doctor of Sciences (Philology), Professor, Head of Department of Stylistics and Rhetoric, Kemerovo State University, Krasnaya St., 6, 650000 Kemerovo, Russia, araeva@list.ru, https://orcid.org/0000-0002-7907-3186

Stanislav I. Li, Postgraduate Student, Assistant of Department of Stylistics and Rhetoric, Kemerovo State University, Krasnaya St., 6, 650000 Kemerovo, Russia, li.stanislav999@yandex.ru, https://orcid.org/ 0000-0003-0576-0511

\section{Информация об авторах}

Людмила Алексеевна Араева, доктор филологических наук, профессор, заведующий кафедрой стилистики и риторики, Кемеровский государственный университет, ул. Красная, 6, 650000 г. Кемерово, Россия, araeva@list.ru, https://orcid.org/0000-0002-7907-3186

Станислав Игоревич Ли, аспирант, ассистент кафедры стилистики и риторики, Кемеровский государственный университет, ул. Красная, 6, 650000 г. Кемерово, Россия, li.stanislav999@yandex.ru, https://orcid.org/0000-0003-0576-0511 